\title{
TEMA SOCIOCIENTÍFICO “CACHAÇA” EM AULAS PRÁTICAS DE QUÍMICA NA EDUCAÇÃO PROFISSIONAL: UMA ABORDAGEM CTS
}

\author{
Míriam Stassun dos Santos * \\ Carmem Lúcia Costa Amaral** \\ Maria Delourdes Maciel***
}

RESUMO: Apresentamos pesquisa qualitativa referente a um estudo de caso, com estudantes da última série do curso técnico de Química integrado do CEFET-MG, adotando temas sociocientíficos (TS) com abordagem CTS nas aulas práticas de Química Orgânica Aplicada. Consideramos os resultados para o TS “cachaça” e observamos interações e diálogos entre professor e estudantes e a didática do professor. Registramos percepções e desenvolvimento de atitudes, valores (PIEARCTS) e habilidades. Na metodologia utilizamos observações, registros, gravações, filmagens e questionários. Ficou evidente a importância do professor na condução das discussões, nas estratégias envolvendo estudantes nas discussões e vivência de situações reais. Ressaltamos a inserção de TS nos currículos de Química como condição fundamental para desenvolver uma educação CTS humanista, e nos cursos de educação profissional, com potencialidades transformadoras.

Palavras-chave: educação profissional, temas sociocientíficos, química, CTS, PIEARCTS.

\section{SOCIOSCIENTIFIC SUBJECT "CACHAÇA" IN PRACTICAL CHEMISTRY CLASSES: A STS APPROACH}

ABSTRACT: This paper introduces a qualitative research over a case study, with students from the last series of integrated Chemistry technician program in CEFET-MG, adopting socioscientific subjetcs (TS) with CTS approach in Applied Organic Chemistry practical classes. We consider the results to the TS "cachaça" and observe interactions and dialogues between teacher and students and the teacher's teaching. We documented perceptions and developing attitudes, values (PIEARCTS) and skills. Methodology-wise, we used notes, records, recordings, filming and questionnaires. The importance of the teacher in the conduct of discussions, in the strategies involving students in discussions and experiencing real situations was evident. We emphasized the insertion of TS in the Chemistry curricula as a fundamental condition to develop CTS education and humanist in professional education courses, with the creation of new possibilities.

Keywords: Professional education, sociocientíficos subjects, chemistry, CTS, PIEARCTS. 
Míriam Stassun dos Santos | Carmem Lúcia Costa Amaral

Maria Delourdes Maciel

\section{INTRODUÇÃO}

As autoras apresentam neste artigo uma análise parcial de uma pesquisa de doutorado, na área de Ensino de Ciências e Matemática, com alguns resultados consistentes colhidos entre agosto e novembro de 2009.

A pesquisa é qualitativa e utiliza como método o estudo de caso. As observações foram realizadas na turma da terceira série do ensino profissional técnico de Química integrado ao ensino médio do CEFET-MG, nas aulas de Química Orgânica Aplicada, totalmente experimentais, nas quais se adotou como programa da disciplina, oito temas sociocientíficos (TS) com abordagem CTS, que considera, como se sabe, a ciência, a tecnologia e a sociedade, em suas inter-relações. Inicialmente, no mês de agosto, foi aplicado aos estudantes um questionário social, econômico, familiar e cultural.

Esta pesquisa foi realizada no Departamento de Química, do Centro Federal de Educação Tecnológica de Minas Gerais - CEFET-MG, Belo Horizonte/MG, local onde uma das autoras trabalha como docente há mais de vinte anos. Essa instituição federal e centenária há quarenta anos oferece cursos técnicos em Química. Nos cinco anos precedentes a este trabalho, ofertou 36 vagas para o curso de ensino profissional técnico de Química de nível médio integrado ao ensino médio, com $3.600 \mathrm{~h}$, integralizado em três anos, em tempo integral, com concorrência para ingresso em vestibular chegando a 24 candidatos/vaga.

O professor escolhido para ter as suas aulas observadas neste estudo de caso foi aquele que apresentou, no relato do desenvolvimento de suas aulas, mais relações com esquemas conceituais e metodológicos que contemplavam as características da abordagem CTS. Para o desenvolvimento das atividades contemplando os TS com enfoque CTS, o professor assume o papel de mediador e facilitador da aprendizagem (ZUIN, 2008). O professor é bacharel e licenciado em Química, doutor, com dez anos de experiência em ensino de Química e em Alimentos, no ensino técnico e na graduação, e integra a linha de pesquisa Química Orgânica Tecnológica: biotecnologia, biodiesel, alimentos e bebidas.

Nesta pesquisa tivemos como objetivos acompanhar: a) o desenvolvimento do controle de qualidade para os temas sociocientíficos (TS) com abordagem CTS, tendo como centralidade o trabalho prático; b) a promoção da discussão desses TS de forma a se envolverem os estudantes e se lhes atribuir um significado real; c) o registro das interações e das discussões entre professor e estudantes nessas aulas práticas; d) a verificação do desenvolvimento de atitudes e valores dos estudantes frente à ciência, à tecnologia e à sociedade; e) a observação e o registro da didática do professor de Química. Para o desenvolvimento da pesquisa foram utilizados procedimentos de observação das aulas práticas e dos seminários apresentados pelos estudantes, registros em caderno de campo, gravações e filmagens, além de questionários (inclusive a versão brasileira do COCTS, o PIEARCTS). 


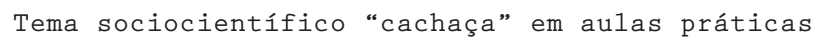

\section{CONTEXTUALIZAÇÃO DO PROBLEMA E REFERENCIAL TEÓRICO}

Alfabetizar estudantes em ciência e tecnologia é hoje uma necessidade do mundo contemporâneo. Não se trata de mostrar maravilhas da ciência, mas de disponibilizar as representações adequadas que permitam ao cidadão agir, tomar decisão e compreender o que está em jogo no discurso dos especialistas (FOUREZ, 2003). Para isso, é esperado que o estudante consiga fazer relações entre os conhecimentos científicos além da sala de aula, buscando compreender a dimensão social da ciência e da tecnologia, tanto do ponto de vista de seus antecedentes sociais como de suas consequências sociais e ambientais (VIEIRA e MARTINS, 2009).

De acordo com Acevedo (2009) e Vázquez e Manassero (2009), uma boa alternativa para a contribuição da escola à alfabetização científica e tecnológica é a introdução das relações entre ciência, tecnologia e sociedade (relações CTS) nas aulas de Ciências. Para López-Cerezo (1996), trabalhar os conteúdos científicos segundo CTS significa ensinar os conteúdos no contexto autêntico do seu meio tecnológico e social, no qual os estudantes integram o conhecimento científico com a tecnologia e o mundo social de suas experiências do dia-a-dia. A proposta curricular envolvendo as relações CTS corresponde, assim, a uma integração entre educação científica, tecnológica e social, em que os conteúdos científicos e tecnológicos são estudados juntamente com a discussão de seus aspectos históricos, éticos, políticos e sócio-econômicos.

Buscando enfatizar o desenvolvimento da capacidade de tomada de decisão consciente e negociada que envolva ciência e tecnologia, apontada por Linsingen (2007), os currículos com enfoque CTS devem ser organizados em torno de temas sociais e as estratégias de ensino recomendadas são centradas na participação efetiva dos estudantes. Os temas são explorados com caráter multidisciplinar, e os conceitos são abordados em uma perspectiva relacional, evidenciandose as diferentes dimensões do conhecimento estudado. Os autores Santos e Mortimer (2003, 2009) mostram a abordagem de temas sociocientíficos no ensino de Ciências, com objetivo de desenvolver atitudes e valores em uma perspectiva humanística. Nessa mesma linha têm trabalhado outros pesquisadores, como Auler (2003); Delizoicov e Auler (2001); Coelho e Marques (2007), buscando incorporar ao currículo discussões de valores e reflexões críticas que possibilitem desvelar a condição humana, ou seja, uma educação em que os estudantes possam refletir sobre sua condição no mundo frente aos desafios postos pela ciência e tecnologia.

Ramsey (1993) defende que para um tema propiciar uma discussão que gere um compromisso social é importante que ele tenha um significado real para o estudante Para esse pesquisador, é a partir da discussão de temas reais e da tentativa de se delinearem soluções para eles que os estudantes se envolvem de forma significativa e assumem um compromisso social. Uma das maneiras de discutir temas reais nas aulas de Ciências, em especial nas aulas de Química, é por meio da experimentação. 
Assim, nesta pesquisa, buscou-se observar se adotar no ensino profissional técnico de nível médio aulas práticas centradas em temas sociocientíficos, com ênfase nas relações CTS, leva a um letramento científico e tecnológico mais efetivo, gera compromisso social, propicia a discussão dos aspectos históricos, éticos, políticos e sócio-econômicos.

\section{DESENVOLVIMENTO DA PESQUISA}

A disciplina Química Orgânica Aplicada, totalmente experimental, foi organizada em torno de oito temas sociocientíficos (TS) e utilizou estratégias de ensino centradas nas orientações CTS, na participação efetiva do estudante e na utilização de temas reais. No início do semestre, o professor apresentou a proposta da disciplina e os TS aos estudantes, que, em duplas, trabalharam com mel, leite, cerveja, Cachaça, detergente, sabão, gasolina e óleo diesel, durante todo o semestre.

Após a definição dos temas sociocientíficos, cada dupla trouxe para o laboratório uma amostra referente a cada tema estudado. Esses TS tornam-se reais à medida que foram escolhidos por eles. $\mathrm{Na}$ maioria das vezes fazem parte de sua vivência cotidiana, e eles escolheram trazer as amostras de vários locais de seu interesse de investigação. Para esses TS, é realizado o controle de qualidade das amostras. Levando-se em consideração os equipamentos e o tempo de aulas (150 minutos/semanais), o professor apresentou as análises gerais e os estudantes decidiram quais seriam aquelas que eles consideraram as mais significativas. Em seguida, em duplas, os estudantes planejaram o cronograma de execução, elaboraram fluxogramas e discutiram a proposta de redução e de tratamento dos resíduos gerados. Para cada TS as análises foram desenvolvidas por todas as seis duplas de estudantes, em cerca de três semanas cada uma, para a amostra trazida.

Durante as aulas experimentais foram promovidas discussões, na tentativa de se delinearem soluções para os problemas identificados, gerados ou trazidos pelos estudantes, e também sobre a influência que a ciência e a tecnologia exercem sobre a sociedade, e ainda, a incorporação das questões de saúde, éticas, políticas, financeiras e ambientais envolvendo o TS. Ao final dos trabalhos de dois TS, os estudantes elaboraram laudos técnicos contendo os resultados para cada amostra e posteriormente apresentaram à turma, em grupos de três, por meio de seminários. Nesses seminários, também foram promovidas discussões/debates sobre os resultados, seus significados e a incorporação das questões sociais, éticas, políticas e ambientais.

Ainda, durante essas aulas práticas procurou-se analisar, por meio de observação, as interações entre estudantes e professor, a didática do professor e a postura dos estudantes frente à metodologia adotada no desenvolvimento da disciplina. Ao final do semestre letivo foi aplicado um questionário contendo oito questões descritivas e uma tabela para se assinalarem as habilidades adquiridas.

Dentre essas questões, analisaremos neste trabalho apenas três, as que te- 
nham como objetivo conhecer-se a percepção de cada estudante sobre a abordagem metodológica adotada na disciplina, o desenvolvimento de atitudes e valores e das habilidades que julgava terem sido proporcionadas na disciplina.

No final do semestre foi aplicada a versão brasileira (Vázquez et al, 2008) do questionário COCTS (Vázquez e Manassero, 2003), utilizado no Projeto Iberoamericano de Avaliação de Atitudes Relacionadas a CTS - PIEARCTS (Vázquez e Manassero, 2006), projeto de cooperação internacional que tem como objetivo investigar as percepções de estudantes e professores brasileiros sobre relações CTS. A adaptação brasileira tem como versão original elaborada por Manassero, Vázquez, Acevedo e Paixão (2008).

A metodologia do PIEARCTS se baseia no uso de questionário de opinião sobre a ciência, a tecnologia e a sociedade (COCTS). A versão brasileira é formada por 30 questões (15 na forma A e 15 na B), articuladas em dois questionários anônimos cuja estrutura foi construída de forma a facilitar a compreensão dos estudantes mais novos e, também a considerar que todas as escolhas de respostas têm seus aspectos positivos, sem classificarmos as respostas como certas ou erradas. Para analisar cada uma das alternativas das possíveis respostas dadas às 15 questões do COCTS, os especialistas classificam as frases como respostas plausíveis (P), ingênuas (I) e adequadas (A). A tarefa é considerar os complementos das afirmativas de cada questão a partir de uma escala valorativa de grau de concordância de 1 a 9, sendo que 1 corresponde a "discordo totalmente", 5 a "indeciso" e 9, "concordo totalmente". Além desses valores, 1 a 9, há outras duas opções, de "não entendo a frase" e "não sei o suficiente para avaliar". Nesse trabalho faremos um recorte e apresentaremos a análise apenas de duas questões selecionadas sobre os conceitos que os estudantes apresentam sobre a ciência e sobre a tecnologia, questões 10111 e 10211, respectivamente do COCTS, segundo Vázquez et al (2008).

\section{DESCRIÇÃO E ANÁLISE DOS DADOS}

O Departamento de Química adota como critério para as disciplinas experimentais do Curso Técnico de Química a divisão das turmas inicialmente de 36 estudantes em três subturmas de, em média, 12 estudantes cada. Para um trabalho mais efetivo e acompanhamento mais próximo, o pesquisador observou os trabalhos desenvolvidos por uma subturma de 12 estudantes, divididos em duplas, durante todo um semestre, de agosto a dezembro, assistindo a todos os blocos de três aulas semanais, durante 20 semanas. Essa subturma era composta de 7 homens e 5 mulheres, na faixa de 17 a 19 anos, 8 oriundos de escolas públicas. A maioria escolheu com quem quer trabalhar nas duplas por afinidade.

Neste trabalho serão apresentados os resultados das observações, do segundo bloco de 9 aulas de 50 minutos, distribuídas em três semanas, sobre o TS "cachaça". Os estudantes trouxeram seis amostras de cachaça das marcas 51 (Pi- 
rassununga), Brotinho, Velho Barreiro, Chico Mineiro e Dona Branca, todas industrializadas e comercializadas em supermercados e bares da Grande BH e a cachaça artesanal de Jabuticaba, preparada artesanalmente em fazenda na cidade de Virginópolis/MG.

Para o TS "cachaça" utilizaram-se três semanas, com blocos de três aulas cada, totalizando 450 minutos. Durante a observação de um bloco semanal de três aulas, totalizando 150 minutos, constatamos que o tempo durante as aulas ficou distribuído de tal forma que, nos primeiros 30 minutos, o professor lançou perguntas desafiadoras aos estudantes à medida que explicava as características básicas da cachaça.

Para a cachaça, as perguntas foram: "Como surgiu a cachaça?”, "Quais são os problemas ambientais gerados pela produção da cachaça?”, "Qual a diferença entre cachaça e aguardente?”, "Qual é a composição da cachaça?”, "Quais são os benefícios e os malefícios trazidos pela cachaça à saúde?”, "Qual é o consumo de cachaça anual por habitante no Brasil?", "Será que o solo influencia na qualidade da cachaça?", "A cana-de-açúcar verde ou madura irá interferir na qualidade da cachaça?", "Por que a moagem da cana deve ser feita até 24 horas após a colheita?", "Existe uma faixa de temperatura para armazenar o caldo de cana?", "Ele pode ser diluído?", "Como garantir um bom processo de fermentação?", "O que é destilado de coração?”, "Para que serve o envelhecimento da cachaça?”, "Qual é a diferença entre cachaça industrial e artesanal?", "Quais são os maiores produtores nacionais e internacionais de cachaça?", "Existe diferença de custo da cachaça industrial para a artesanal?”, "Qual é o custo de um litro de cada tipo de cachaça ?”, “Quantas marcas de cachaça existem atualmente?”, “Quantos produtores?”, “Quantas pessoas empregadas?”, “Como é o mercado internacional?”, "Quais são os contaminantes que você espera encontrar na sua amostra de cachaça?". À medida que comentava fatos históricos, consumo da bebida no Brasil, exigências legais, presença no mercado nacional e internacional, e processos de produção, o professor explicava algumas características físico-químicas básicas da cachaça, suas análises e detalhava o significado de cada técnica.

Nos dez minutos seguintes, os alunos decidiram juntamente com o professor quais seriam as análises que a turma iria realizar e fizeram o planejamento experimental, em duplas. Para o TS "cachaça” os estudantes escolheram executar as seguintes análises: especificação das amostras e tipo das embalagens, densidade (método do densímetro e do balão), grau alcoólico real (alcoômetro), extrato seco (estufa), determinação de cobre (qualitativo e quantitativo - espectrofotômetro), acidez total (titulação ácido-base), acidez fixa (estufa, titulação). Consideram-se o tempo de aula e os equipamentos disponíveis no laboratório a realização das análises.

Em seguida, os estudantes utilizaram o tempo restante nas análises, discussão dos resultados e troca de informações entre eles e com o professor, gerando questionamentos intrínsecos às análises e, em vários momentos, os am- 
pliando para o dia-a-dia, contando histórias sobre fazendeiros, produtores e familiares, discutindo causas e consequências do alcoolismo.

Nas observações das aulas constatou-se que a visão que satisfaz aos estudantes não é somente a que existe nos registros dos procedimentos técnicos. Eles também desenvolvem habilidades processuais e técnicas, tomam decisões, enfatizam a prática para chegarem à teoria, buscam implicações sociais dos problemas apresentados, lidam com problemas verdadeiros nos seus contextos sociais, concordando com Linsingen (2007).

A cada final do período de três aulas ou ao final de um TS, os estudantes tratam os resíduos gerados, limpam as bancadas e lavam as vidrarias utilizadas. Para a análise da cachaça foi necessário tratar os resíduos gerados de ácido oleico e neutralizar as soluções residuais de hidróxido de sódio - $\mathrm{NaOH}$. Nas duas semanas seguintes, os alunos dedicaram-se a realizar as análises combinadas sob a orientação do professor e, ao final dos dois TS, cachaça e cerveja, agendaram uma apresentação de seminários, em grupos de três, e a entrega do laudo técnico contendo os resultados das análises das amostras da dupla.

Durante o seminário, na apresentação dos estudantes pudemos constar as diversas relações entre CTS e o TS escolhido. Os estudantes responderam a cada pergunta que o professor inicialmente fez, mostrando a importância da cachaça, seu mercado, enfatizando a qualidade, os tipos de cachaça e as suas diferenças, o processo de fabricação da bebida artesanal e da industrializada, as possíveis interferências na qualidade: solo, mês de colheita, queimadas, uso de cana verde ou madura, tempo de moagem após colheita, diluição ou não, temperatura de armazenagem do mosto, pH, adição ou não de sais minerais, tipos de fermentos, teor de álcool, fração de destilação a ser recolhida, dentre outros fatores. Levantaram os problemas ambientais oriundos da produção da cachaça, destacando os contaminantes, as práticas de fabricação ruins - fermentação e destilação e possíveis adulterantes; a composição e o consumo; a produção mundial de Cachaça. Abordaram a importância econômica da cachaça para o Brasil no cenário mundial (produção nacional e competitividade da cachaça brasileira), apontaram a cachaça como o terceiro destilado mais consumido no mundo e terminaram citando uma frase antiga de um jurista, mas que exprime o valor atual do produto brasileiro:

"Quando o Brasil criar juízo e se tornar uma potência mundial, será a cachaça, e não o whisky, a bebida do planeta." (SOBRAL PINTO)'

As discussões entre estudantes e o professor aumentavam a cada semana de aula e promoveram uma integração do conhecimento científico com a tecnologia e o mundo social de suas experiências do cotidiano. Os participantes estabeleceram relações entre conhecimentos científicos além da sala de aula, buscando, como preconizam Vieira e Martins (2009), compreender a dimensão social da ciência e da tecnologia, bem como suas consequências sociais, políticas, éticas e am- 
bientais, como citam Auler (2003); Delizoicov e Auler (2001); Coelho e Marques (2007).

O outro grupo apresentou, no seminário, os resultados das análises das amostras quanto às características físico-químicas seguindo a Instrução Normativa n0 13 de 30 de junho de 2005, que estabelece os Padrões de Identidade e Qualidade (PIQ's) para a Aguardente de Cana e Cachaça. Diante dos resultados encontrados para as seis amostras, os estudantes concluíram que "todas estão dentro dos parâmetros estabelecidos pela legislação para o produto; porém, ressaltam que para confirmar a qualidade de todas as cachaças é necessário realizar os demais testes quantitativos".

Do questionário aplicado foram selecionadas para registro as respostas mais completas. Em relação à abordagem metodológica os estudantes responderam à questão "A abordagem metodológica adotada na disciplina de Química Orgânica Aplicada auxilia para o melhor entendimento do seu papel como cidadão crítico e reflexivo e contribui para o desenvolvimento como futuro profissional da Quimica? Justifique.":

Estudante 10 - "O embasamento teórico, dado antes das práticas, aliado a autonomia nos dada durante o experimento, nos faz desenvolver uma visão crítica que contribui para o papel do cidadão e para o trabalho de um químico";

Estudante 7 - "Percebi que cada um em sua função contribui com o desenvolvimento da sociedade e no meu desenvolvimento como profissional, auxiliou para ganhar responsabilidade e conbecimento";

Estudante 8 - "Possibilita um pensamento de ciência aplicada em prol de melhorias para a sociedade";

Estudante 9 - "Tem-se uma melhor reflexão sobre as práticas e ações realizadas nela";

Estudante 12 - "Adquiri experiência em laboratório e trabalho em equipe, bem como aprendi sobre o meio ambiente e a sociedade".

Em relação à ética, houve as seguintes respostas à questão "Vocêpercebeu a influência da ética sobre a Ciência e a Tecnologia? Cite em quais momentos.”:

Estudante 10 - "Nos momentos de análise, a ética é de suma importância, a fim de que os resultados sejam divulgados da maneira correta";

Estudante 7 - "Ao emitirmos um laudo, devemos ter a certeza dos resultados que obtivemos e não podemos manipular estes resultados, já que permitir que produtos fora dos padrões sejam comercializados poderia prejudicar a saúde dos consumidores";

Estudante 8 - "Na verificação da falta de ética de alguns produtores ao comprometerem, conscientemente, a qualidade dos produtos fornecidos ao consumidor";

Estudante 5 - "Na verificação de possiveis alterações nas amostras analisadas e, comprovadamente, feitas de má fé";

Estudante 11 - "Devem-se gerenciar residuos e ter-se responsabilidade na análise de produtos".

Nas observações e nas gravações das aulas percebe-se que a abordagem comunicativa entre professor e estudantes foi do tipo interativa/dialógica, segundo Scott, Mortimer e Aguiar (2006). Isso significa que o professor e estudantes exploraram ideias, formularam perguntas autênticas e ofereceram, consideraram e 
trabalharam diferentes pontos de vistas. Para saber se os estudantes também haviam percebido esse tipo de interação, eles responderam as questões "A metodologia adotada proporcionou maiores interações discursivas entre o professor e os estudantes em sala de aula? O equilíbrio entre essa abordagem e a de autoridade adotada pelo professor é benéfico? Qual tem sido o papel do professor?":

Estudante 11 - "O desenvolvimento do projeto de pesquisa, o tema, possibilita uma visão mais ampla dos métodos analíticos e da sua aplicação na sociedade de uma forma geral";

Estudante 8 - "Com esse tipo de abordagem, o professor atua em uma melhor efetivação do aprendizado e na compreensão dos temas abordados";

Estudante 10 - "Com a autonomia que nos é dada, podemos pensar, juntamente com o professor, nos resultados obtidos e o porquê destes. O professor adota uma postura de esclarecedor, deixando-nos raciocinar durante os experimentos, o que contribui para nosso desenvolvimento profissional";

Estudante 7 - "O professor discute os assuntos em sala, tira nossas dúvidas, gerencia o laboratório e trabalha de forma a dar oportunidade para a participação dos estudantes";

Estudante 5 - "A abordagem é muito benéfica, pois nos propicia uma visão mais ampla a respeito do tema tratado, ou seja, o professor tem o papel de nos guiar em um caminho antes nunca trilhado".

Nas respostas dos estudantes a abordagem metodológica adotada possibilitou um embasamento teórico anterior à prática, melhor reflexão sobre as práticas e ações realizadas nelas. Ela traz uma visão mais ampla e crítica, tornando o aprendizado mais efetivo tendo significado real para o estudante (Ramsey, 1993), potencializando a autonomia e a participação dos estudantes, promovendo o trabalho em equipe e contribuindo para a formação do cidadão, corroborando López-Cerezo (1996). Ainda, potencializa uma integração entre a educação científica, tecnológica e social e, consequentemente, o melhor entendimento do seu papel como cidadão crítico e reflexivo e contribui para o seu desenvolvimento como futuro profissional da Química. Constatamos que valores como a ética, atitudes e responsabilidade social também foram desenvolvidas com a abordagem CTS através de TS, conforme Santos e Mortimer (2002 e 2009). Os estudantes registraram a capacidade do professor como orientador, gerente do laboratório, proporcionando a efetivação do aprendizado e a tomada de decisão.

$\mathrm{Na}$ tabela de habilidades, os estudantes registraram na totalidade das 33 respostas que, todas as habilidades desenvolvidas nessas aulas práticas são básicas para práticas educativas com enfoque CTS, segundo Yager (1991). São elas: identificação de problemas com interesse/impacto social; aprendizagem enfocando o futuro; exercício da cidadania ao se tentarem resolver problemas que os próprios alunos identificaram; envolvimento ativo do estudante ao buscar informações úteis; seleção de procedimentos experimentais; trato com problemas verdadeiros no contexto real; busca, principalmente, por implicações sociais dos problemas tecnológicos; construção de hipóteses; planejamento; comparação e diferenciação; tomada de medidas; elaboração de conclusões; controle de variáveis; comu- 
nicação; dedução; interpretação de dados; classificação; observação e uso de relação tempo/espaço.

$\mathrm{Na}$ aplicação do questionário PIEARCTS (versão brasileira), a questão 10111 recebeu quase a totalidade do percentual de indicação (32 respostas) como aquela considerada como adequada pelos autores: ideias e técnicas para conceber e fazer coisas; para organizar os trabalhadores, as pessoas de negócios e os consumidores; e para o progresso da sociedade. Da mesma forma, as respostas consideradas por eles plausíveis relacionam a tecnologia com novos processos ou com a aplicação para o uso diário (31 respostas); ainda, a que a identifica com a produção de artefatos (33 respostas), ou seja, a crença de que a tecnologia vem da engenharia.

Através das respostas ao PIEARCTS, os estudantes perceberam que a tecnologia está relacionada à investigação e à engenharia. Entenderam que o conhecimento tecnológico resulta na elaboração de instrumentos, ferramentas e aplicações para questões distantes ou próximas de sua vida cotidiana, desde o desenvolvimento de corações artificiais e veículos espaciais até os computadores, celulares, ipods e outros aparelhos.

Em relação à questão 10111, a totalidade dos estudantes (33 respostas) concorda que ciência é, principalmente, um corpo de conhecimentos, como princípios, leis e teorias que explicam o mundo que nos rodeia (matéria, energia e vida) e, também, um processo de investigação sistemático e o conhecimento resultante. As respostas plausíveis apresentaram alto índice de indicação (31 respostas). Os estudantes consideram as respostas que contêm uma visão de ciência complexa, de cunho político, social e ambiental; que vai além do caráter exploratório. Eles entendem que o conhecimento científico promove e/ou beneficia a melhoria da qualidade de vida.

\section{CONSIDERAÇÕES FINAIS}

Ficou evidente que a experiência do professor e as explicações e direcionamento metodológico sobre o uso dos elementos CTS facilitaram e contribuíram de forma significativa para a abordagem mais sistemática dos TS. Nesse sentido, os resultados da investigação apontam que a abordagem dos TS em uma perspectiva mais ampla de formação para a cidadania depende das concepções dos professores e da sua prática pedagógica. À medida que, a partir de experiências diversificadas, o professor as implementa na sua prática em sala de aula, ele adquire autonomia e segurança para a adoção de novas metodologias. Nesse sentido, os resultados evidenciaram que a experiência do professor é condição facilitadora para o sucesso de suas estratégias em sala de aula.

Os dados obtidos no estudo de caso nos fornecem indicadores de que os TS potencializaram o aumento das interações dialógicas em sala de aula. Ao introduzir a escolha dos TS, os estudantes apropriam-se deles e estabeleceram relações com fatos do cotidiano e discussão. Para que isso aconteça o professor deve apresentar formação ampla, postura aberta, disposição para ouvir os estu- 
dantes, domínio para gerenciar o laboratório, as análises e o tempo de aulas. O uso de questões desafiadoras contribuiu para que o professor, com experiência em outras áreas de ensino, conseguisse iniciar o movimento dialógico contemplando os horizontes conceituais dos estudantes.

Os dados indicam, portanto, que os TS podem ter uma função no ensino de Química, contribuindo para o estabelecimento de mais interações discursivas de natureza dialógica em sala de aula. O equilíbrio entre essa abordagem e a de autoridade e os seus usos em contextos apropriados parece contribuir para a produção de sentidos pelos estudantes. Há que se notar, no entanto, que o professor usava abordagens dialógicas para discutir os TS, e não os conteúdos químicos propriamente ditos.

Para o TS "cachaça" os dados mostram que algumas estratégias didáticas, como perguntas desafiadoras, contribuíram para o estabelecimento do processo interativo. Associado a isso, a realização de discussões/seminários em grupos, durante e após as aulas, se revelou mais uma estratégia que contribui para o envolvimento dos estudantes.

A observação das análises dos TS e os questionários respondidos reforçaram que a abordagem desses aspectos, além de potencializar o processo de interação em sala de aula, possibilita o surgimento de situações vivenciais, a discussão de atitudes e valores, e de conceitos de ciência e de tecnologia. Várias intervenções sobre situações do cotidiano ou de curiosidades e ainda, em relação às atitudes e valores, foram apresentadas pelos estudantes e reforçadas pelo professor durante as aulas e os seminários e tiveram desdobramentos econômicos, sociais e ambientais. Nesse sentido, o professor proporciona uma abordagem humanística, explorando temas escolhidos pelos estudantes e da vivência deles, que puderam emergir nas discussões. e introduz questões de valores e atitudes.

Em relação à ciência e à tecnologia,, segundo a análise das respostas do PIEARCTS, ficou evidente que os estudantes apresentam conceitos completos sobre ciência e tecnologia, diferentemente dos resultados do projeto internacional onde estudantes do ensino médio apresentam conceitos de senso comum.

Todos esses resultados apontam para a importância da inserção de TS nos currículos do ensino profissional técnico de Química de nível médio, como condição fundamental para o alcance do objetivo da formação da cidadania em cursos que visem à alfabetização científica na perspectiva humanística, reflexiva e crítica; ainda, mostram o enfoque CTS como fonte fecunda para a análise do processo educacional das áreas técnicas, com potencialidades transformadoras.

\section{NOTAS}

${ }^{1}$ http://www.assbb.org.br/historia/cachaca.html 


\section{BIBLIOGRAFIA}

ACEVEDO, J.A. Cambiando la práctica docente en la enseñanza de las ciencias a través de CTS. Borrador, 13, p. 26-30, 1996. En línea en Sala de Lecturas CTS+I de la OEI. Disponível em: <http://www.campusoei.org/salactsi/acevedo2.htm>. Acesso em: 11 set. 2009.

AULER, D. Alfabetização científico-tecnológica: um novo "paradigma"? Ensaio: Pesquisa em Educação em Ciências, Belo Horizonte, v. 5, n.1, p.1-1, 2003.

AULER, D.; DELIZOICOV, D. Alfabetização científico-tecnológica para quê? Ensaio: Pesquisa em Educação em Ciências, Belo Horizonte, v.3, n.1, pp.105-115, 2001.

COELHO, J. C., e MARQUES, C. A. Contribuições freireanas para a contextualização no ensino de Química. Ensaio: Pesquisa em Educação em Ciências, Belo Horizonte, v.9, n.1, pp.1-17, 2007.

FOUREZ, G. Crise no ensino de Ciências? Investigações em Ensino de Ciências, Belo Horizonte, v.8, n.2, pp. 109-123, 2003.

LINSINGEN, I. VON. Perspectiva educacional CTS: aspectos de um campo em consolidação na América Latina. Ciência \& Ensino, São Paulo, v.1, número especial, 2007.

LÓPEZ, J. L. L. e CEREZO, J. A. L. Educación CTS en acción: enseñanza secundaría y universidad. In M. I. G., GARCIA, J. A. L., CEREZO e J. L., LOPEZ (Orgs.). Ciencia, tecnología y sociedad: una introducción al estudio social de la ciencia y la tecnologia. Madrid: Editorial Tecnos, p. 225-252, 1996.

SANTOS, W. L. P. dos, e Mortimer, E. F. Aspectos sociocientíficos em aulas de química e interações em sala de aula. In: ENCONTRO INTERNACIONAL LINGUAGEM, CUltura E COGNIÇÃO, 2, 2003, Belo Horizonte. Anais..., Belo Horizonte, 2003. Abordagem de aspectos sociocientíficos em aulas de Ciências: possibilidades e limitações. Investigações em Ensino de Ciências, 14(2), pp.191-218, 2009. SCOT'T, P. H.; MORTIMER, E. F. e AGUIAR, O. JR. The tension between authoritative and dialogic discourse: a fundamental characteristic of meaning making interactions in high school science lessons. Science Education, New York, v.90, n.7, p.605-631, 2006.

VÁZQUEZ, A. e MANASSERO, M.A. La presencia de los temas CTS en el curriculo a partir de los resultados del TIMMS. Revista CTS, OEI, 28-34, 2009.

MANASSERO, M.A., ACEVEDO, J.A. e M. F. PAIXÃO. COCTS - PIEARCTS

- Forma 1 e Forma 2. Versão 2.1, 2008. Disponível em: <http://www.oei.es/COCTS/ por/index.html>. Acesso em: 08/12/2009.

; MANASSERO, M.A. Proyecto Iberoamericano de Evaluación de Actitudes Relacionadas com La Ciencia, La Tecnología y La Sociedad (PIEARCTS). Ministério de Educación y Ciencia/Espanha, 2006.

; MANASSERO, M.A. y ACEVEDO, J. A. Cuestionario de opiniones sobre ciência, tecnologia i societat (COCTS). Views on Science, Technology, and Society Questionnaire. Princeton, NJ: Educational Testing Service. 2003. Em: http://www.ets.org/testcoll/. Acesso em 10/09/2009.

VIEIRA, R.M e MARTINS, I.P. Práticas de professores do Ensino Básico orientadas numa perspectiva CTS-PC, Revista CTS, p.79-86, 2009.

RAMSEY, J. The science eduction reform movement: implications for social responsibility. 


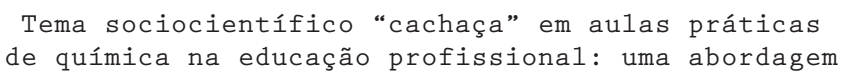

Science Education, v.77, n.2, p.235-258, 1993.

ZUIN, V.G.; FREITAS, D.; OLIVEIRA, M. R.G. e PRUDÊNCIO, C.A.V. Análise da perspectiva ciência, tecnologia e sociedade em materiais didáticos. Ciência \& Cognição, v.13, n.1, p.56-64, 2008.

YAGER, R.E. The centrality of practical work in the Science/Technology/Society movement. In: WOOLNOUGH, B.(Ed.). Practical Science. England: University Press, 1991.

Data de recebimento: $15 / 06 / 2010$

Data de aprovação: 05/08/2011

Data da versão final: 12/09/2011 